\title{
45 ANOS DE SALA DE AULA: PROFESSOR HORISTA E PESQUISADOR
}

45 YEARS OF CLASSROOM AS AN HOURLY-WAGE TEACHER AND RESEARCHER 45 AÑOS DE CLASES: PROFESOR HORISTA E INVESTIGADOR

Osmar de Souza

Doutor em Letras pela UNESP. Docente do Programa de Pós-Graduação em Educação da FURB.

Programa de Pós-Graduação em Educação Fundação Universidade Regional de Blumenau (FURB) Blumenau - SC - Brasil

\section{Endereço:}

Rua Antônio da Veiga, 140 Victor Konder - Blumenau - SC CEP: 89030-903

\section{E-mail:}




\section{A CONSTITUIÇÃO DO PROFESSOR}

m março deste ano, completei 45 anos de sala de aula. Nunca me afastei por um ano inteiro da sala de aula, mesmo quando fiz mestrado e doutorado. No Mestrado trabalhava direto e aos finais de semana ia a São Paulo. No Doutorado, recebi uma bolsa por dois anos, que não me impedia de trabalhar, era mais uma ajuda de custos. Nesses dois anos, trabalhei mais em cursos de especialização, menos em graduação, ou no ensino fundamental. Ministrei algumas disciplinas na Univali em períodos de recesso, julho ou fevereiro, assim o restante do ano dedicavame à pesquisa e às atividades de eventos da área. Nos dois últimos anos do Doutorado, trabalhei tanto no ensino fundamental quando na graduação e na pós, especializações. Do lugar onde me encontro hoje, reputo este retorno decisivo para a consolidação de aspectos teóricos que vinha estudando, quando confrontados com práticas de sala de aula. Só sobre este período ainda estou devendo um artigo à academia.

Neste texto, quero pontuar as condições de possibilidades, num sentido foucaultiano, que permitiram me constituir pesquisador e formar pesquisadores e o que esse processo interfere na sala de aula. Quero me limitar ao tempo em que trabalhei na UNIVALI, Itajaí-SC, período que vai de 1977 a meados de 2004. Mas para que se tenha uma noção mais completa do lugar de onde falo, vou tentar resumir minha atuação em sala de aula. Iniciei como professor de adultos, no antigo Movimento Brasileiro de Alfabetização (MOBRAL). Era uma escola de interior, as aulas eram à noite, a maioria dos alunos eram trabalhadores do campo. Depois fui professor de escola multisseriada de Língua Portuguesa e Inglesa, no que equivale hoje ao sexto e nono anos; no ensino médio também atuei com essas disciplinas.

No ensino superior, atuei na graduação com disciplinas de Letras, Linguística, Psicolinguística, Sociolinguística, Literatura Brasileira, Portuguesa e Teoria Literária. Na Pedagogia, com Filosofia, Filosofia da Educação e História da Educação. Na pós-graduação, na UNIVALI, meu ingresso se dá pelas especializações, em várias áreas, Direito, Administração, Educação, Letras, em geral, com disciplinas de Metodologia da Pesquisa. Esta disciplina também me marcou o ingresso no stricto sensu em Ciência Jurídica e em Turismo e Hotelaria. Na Educação, fiz parte de um grupo de professores, vindos de diferentes formações que, após demoradas 
reuniões e reflexões, definiu uma diretriz ao programa de Mestrado em Educação. Neste atuei com mais dois professores de perspectivas metodológicas distintas, abordando a pesquisa em educação. Sobre esta experiência também ainda devo um artigo, talvez em parceria com os outros dois colegas, se isto for possível. Nos últimos anos em que trabalhei na UNIVALI, de 1997 a 2003, coordenei a Editora da UNIVALI, que respondia também pelas revistas acadêmicas à época. Fui essencialmente professor horista, como professor e como atividades de gestão.

Este espalhamento de atuações ainda hoje tem consequências em minhas atuações na orientação e em aulas. Resisto muito a filiações, nomeadamente teóricas. Sinto-me mais confortável quando posso aprender e ensinar, absorvendo contribuições de abordagens muitas vezes conflitantes entre si. Falo um pouco mais disso adiante.

Ressalvo ainda que em minha graduação de Letras, no período de 1971 a 1974, não havia a disciplina de Metodologia de Pesquisa. Isso implica que minha formação foi essencialmente para a sala de aula e numa área bem específica, trabalhar com ensino de línguas e respectivas literaturas. A formação pedagógica eram as mínimas exigidas pela legislação da época e o estágio se resumia ao último ano. Se houve, ao longo dos meus primeiros vinte anos de sala de aula, atitudes de pesquisador, refere-se àquilo de que precisava para ministrar minhas aulas. Penso que esta minha história se aproxima da imensa maioria dos professores, tanto de escolas públicas quanto privadas, num significativo número de escolas públicas brasileiras.

\section{A CONSTITUIÇÃO DO PESQUISADOR}

A sumarização anterior não me inviabilizou atitudes de pesquisador, mesmo que pense num sentido lato. Quem não lembra os trabalhos individuais e em grupos, comumente chamados de pesquisa? Além disso, o trabalho com diferentes disciplinas e em diferentes áreas tornaram-me um leitor "não disciplinar", em que sempre precisei pensar no "outro". O aluno em sala de aula e aquele que me procurava para auxiliar em monografias (não havia a cultura de artigos, como se assiste nos últimos tempos) sempre tiveram em mim um interlocutor, até certo ponto privilegiado porque aprendia também. Essas atitudes podem ser sintetizadas em duas virtudes, destacadas por Umberto Eco no conhecido livro "Como se faz uma 
tese em ciências humanas": humildade e orgulho. Humildade que nos primeiros anos às vezes ficaram ausentes, por uma formação autoritária que antecede à vida escolar e aos primeiros passos profissionais na educação. À medida que os tempos e os espaços são ocupados a pesquisar e por leituras sempre renovadas de orientações pedagógicas ou cursos de formação, a humildade se manifesta na relação com o aluno, numa atitude sempre fundamental, a de saber ouvir, o que também é determinante no pesquisador. Esta atitude eu só fui me aprofundar no doutorado. Adiante explico por quê.

Por outro lado, posso dizer que tenho orgulho de muitas ações pedagógicas realizadas, muitas delas derivadas das pesquisas. Orgulho de compreender e de acompanhar as histórias de outros. Este é um processo muitas vezes lento. Há conceitos, representações que demorei anos para proceder a certa verticalização. Um exemplo que posso citar é o de "coesão" e de " coerência", conceitos com que trabalhei no meu doutorado. Um amigo meu havia me dito, por ocasião de um curso que ministrou no lato sensu na UNIVALI, que esses conceitos são pequenos perto da complexidade do que é ler e escrever. Quando voltei para a sala de aula, vi na prática que os alunos até observavam elementos mínimos de coesão e alguma coerência no que escreviam, mas não significava um texto adequado a uma audiência pública. Registro isso para dizer que o que pesquisei vai para a sala de aula, mas não vai com o mesmo movimento e o mesmo sentido. Eu não teria esta percepção se não tivesse pesquisado e se não tivesse testado. Esta consciência que tenho hoje fica fortalecida quando leio artigos da saudosa Maria Célia Marcondes de Moraes (MORAES, 2001, 2009), quando se posiciona contra o recuo da teoria nas pesquisas em educação, ou quando pontua que a teoria faz diferença.

Essas duas virtudes foram sempre perseguidas por mim, tanto em meus escritos quanto em minhas orientações. Desde os trabalhos nas especializações, jamais impus o tema, o problema a ser pesquisado. Sempre parti do princípio que a constituição do pesquisador é um coletivo, de onde vem os princípios organizadores de alguém que procura uma especialização, ou mestrado e doutorado mais adiante. Influenciado por Paulo Freire no campo da Educação e de autores que se debruçam sobre a linguagem numa perspectiva históricocultural, como os que pertencem ao conhecido Círculo de Bakhtin, a interação depende de conhecimentos e experiências anteriores e a partir dessas novos conhecimentos se produzem para todos que participam dos eventos, seja uma aula ou o acompanhamento de uma pesquisa. 
Quando pensei em delimitar nesta seção a constituição do pesquisador, associava isso a uma questão objetiva e concreta: as condições, de horários, com disciplinas, reuniões, imprevistos familiares e pessoais. Éramos todos horistas quando no início do Mestrado em Educação. A isso se acrescentam trabalhos de gestão, no meu caso à frente da Editora, como mencionado. Há também fatores externos à Universidade, que, por questão de foco, não serão mencionados.

Minha formação de pesquisador se deu dentro deste contexto. Se for pensar em termos estratégicos de produção, na conhecida tríade, planejamento, execução, avaliação, nas condições que me foram oferecidas e dos colegas, não dá para pensar nesta lógica. Muitos textos foram nascendo em espaços e tempos nada ortodoxos. Durante uma viagem de ônibus ou de avião, em intervalos de aulas, em feriados breves ou prolongados. Para um número considerável de professores, como eu, a alternativa se torna a sala de aula. Ou se faz pesquisa cotidianamente ali ou se limita a um tempo para um título acadêmico e corre o risco de terminar por ali. Tentei sempre fugir desta última alternativa.

Adiante retomo essas condições para refletir numa dimensão simbólica, à luz do sociólogo Pierre Bourdieu.

A seguir tento refletir um pouco sobre a ambiguidade e às vezes dualidade, ser professor e pesquisador.

\section{A CONSTITUIÇÃO DO PROFESSOR-PESQUISADOR}

Posso dizer que, do ponto de vista formal, comecei a me formar pesquisador e contribuir na formação de pesquisadores na orientação em cursos de especialização. Entre 1990 e 1992, cumpria os créditos para o Doutorado. Digo isso porque no Mestrado não desenvolvi pesquisa de campo. Fiz pesquisa bibliográfica, o que também fez parte dessa construção. Também implica seleção, sistematização, delimitação de objetivos. Decorre disso que, nas primeiras orientações, gastei muito tempo e muita saliva com questões de normas da ABNT, formatando textos. Não entrava muito no mérito do conteúdo, porque muitas orientações eram de profissionais de outras áreas. Com este registro, não quero menosprezar o aspecto formal. Este nos ensina muito a termos cuidado, respeito com quem vai ler os nossos trabalhos, em forma de relatórios ou de artigos. Então, preciso fazer um ajuste com o leitor aqui, quando falo de pesquisador, 
na minha formação. Quero pontuar o pesquisador que vai a campo, vai nos espaços sociais, que vive as contradições das práticas sociais ligadas à educação de modo mais específico. Minha experiência em Mestrados de Ciência Jurídica e Turismo e Hotelaria, na UNIVALI, se aproxima das especializações pelo fato de ser completamente off sider. Tornei-me um leitor que aprendi com mestrandos ao mesmo tempo que emprestava meus conhecimentos gramaticais e de normas. Parcerias sempre deixam muitos conhecimentos incidentais (CASSANY, 1998), entendidos como aqueles que não tínhamos propósitos, mas incorporamos.

Do tempo em que trabalhei na UNIVALI, orientei sete dissertações, entre elas a primeira que foi defendida no então recente programa. Naquele momento não havia um projeto que ancorasse as dissertações. Todas foram ligadas à linguagem, mas com focos espalhados. Mesmo com esta ressalva, é possível extrair deste período, que vai de 2002 a 2004, ensinamentos que peço licença para compartilhar com o leitor, os quais se referem à constituição do pesquisadorprofessor a partir de então.

Entre tantos aspectos, destaco:

a) Persistência: pesquisar e ensinar exigem constantes revisões, mudanças de focos, novos autores, novas abordagens. Todos os orientandos já eram professores, muitos atuavam no ensino superior, alguns com mais de 30 anos de magistério. A persistência se deu no sentido de uma mediação para uma mudança de pensamento, de professor para pesquisador. Houve até quem após a qualificação pensasse em desistir, tais foram as críticas recebidas, não sem aviso antecipado de minha parte. Este aprendizado levo ainda hoje para a sala de aula, jamais desistir de um aluno, mesmo quando todas as condições apontam para isso.

b) Derivado disso, há outra consequência: ensinou-me a "não julgar". Aprendi a entender o discurso dos alunos, fossem eles orais ou escritos. O que os levava a produzir este e não outro dizer. Este cuidado comecei a levar também para a sala de aula. Cometi muitas vezes o risco de julgar muito rapidamente os alunos nos seus dizeres, nas suas condutas, mas nem sempre me colocado em diálogo com esses alunos. $O$ que tem me policiado neste sentido e que levo para minhas práticas é primeiro ouvir e depois dialogar com o orientando e com ele encontrar respostas que, em pesquisas, tendem a ser provisórias. Aprendi a desenvolver uma atitude de colaboração. Paulo Freire me ajudou neste sentido a entender o processo de aprendizagem como dialógico, colaborativo, o que não isenta o 508 
professor de mediação e ajuste em conformidade com aquilo que a área ou as áreas chegam a consensos, sempre muito frágeis.

c) Aprendi também a desenvolver um sentido de comunidades discursivas, expressão que li em tantos textos, mas que a vivência com diferentes áreas de conhecimento permitiu prestar atenção nos discursos recorrentes em determinadas áreas, como Direito, Administração, Saúde, mas também os conflitos, os silêncios políticos (ORLANDI, 1998). Em todas as áreas há os discursos interditados, há os discursos privilegiados, os discursos polêmicos/polissêmicos. E nisso a educação é um campo fértil também. Um pouco dessas tensões foram objeto de orientações deste período. A constituição do pesquisador-professor passa por um componente de alteridade que transcende à área da Educação. Entre outras, destaco a voz de professores que, quando pesquisados, correm o risco de ter os seus dizeres deslocados para interpretações subjetivas. As mediações se encaminham para conter isso, tanto na pesquisa quanto na ação em sala de aula.

Possivelmente, um dos aspectos que transforma o professor-pesquisador seja a consideração de uma dimensão simbólica, objeto da próxima seção.

\section{A CONSTITUIÇÃO DO PESQUISADOR-PROFESSOR NA DIMENSÃO SIMBÓLICA}

Aproprio-me neste tópico, concluindo este texto, de uma contribuição de Bourdieu ao distinguir os bens materiais dos bens simbólicos, ou capital material e capital simbólico. Nesta dimensão, posso pensar a minha constituição pessoal e profissional em termos materiais e simbólicos. Com isso quero dizer que a constituição pessoal e profissional é sempre relativa, quando penso em pesquisa, no sentido de que vai sempre depender de um valor que atribuo àquilo que estou perseguindo. Neste sentido, pouco importa o quanto tempo eu gastei ou onde eu desenvolvi a pesquisa, mas o que esta foi mexendo comigo, com os conhecimentos prévios confirmados ou desestabilizados. Quero dizer, pela experiência acumulada, tanto nas minhas produções quanto nas orientações, que ao iniciar um projeto de pesquisa, este vai me acompanhando o tempo todo, em todos os lugares. Mesmo que eu por vezes quisesse me distanciar, aquela exigência ia me interpelando. Podia ser um intervalo de aula, uma hora de almoço com colegas, uma confraternização. Se houvesse alguém por perto que vivia situação semelhante, voltava o pensamento, a conversa para as questões em foco. 
Esta dimensão fez-me às vezes cético diante de algumas filiações teóricas e suas camadas discursivas, provavelmente como uma consequência do que mencionei na primeira parte deste texto. Privilegio hoje uma perspectiva de linguagem histórico-cultural e uma abordagem da educação na mesma direção, mas sempre estou aberto e pronto para novos enfoques, que passam também por outras áreas, sem me afastar daquela problemática sobre a qual esteja num determinado momento debruçado. Tenho me permitido evitar reducionismos a que venho assistido em muitas publicações e em bancas. Uma das evidências do reducionismo pode ocorrer, como afirma Moraes (2001; 2009) quando discorre sobre o"recuo da teoria".

Como leitor, sempre prestei muita atenção aos autores que fundamentavam o pensamento de determinadas obras. Os autores que mais contribuíram foram aqueles que se permitem uma liberdade de cotejamento. Estabelecem uma garimpagem em campos nem sempre muito pacíficos, como ramos da filosofia, da sociologia, da psicologia, entre tantos, mas marcam posições, e esta predição hoje se incorporou às ações tanto de sala de aula quanto na orientação de pesquisas. Tento oferecer ferramentas para que os sujeitos falem, pronunciemse com autoridade, com autoria.

A dimensão simbólica implica uma exigência sempre maior no investimento pessoal em termos de aprofundamento teórico. A acomodação não faz parte de quem se deixa mergulhar nesta dimensão. Por isso, mesmo agora, aposentado, quando poderia procurar outras atividades, ainda me vejo interpelado a realizar sempre novas leituras, perseguir novos projetos. Enquanto houver este discernimento, pretendo continuar.

\section{REFERÊNCIAS}

BAKHTIN, M. Marxismo e filosofia da linguagem. São Paulo: Hucitec, 1986.

BOURDIEU, P. Troca das economias simbólicas. São Paulo: Perspectiva, 1987.

CASSANY, D. Describir el escribir: como se aprende a escribir. Trad. Osmar de Souza. Itajaí-SC: Ed. Univali, 1998.

FOUCAULT, M. A ordem do discurso. São Paulo: Loyola, 1996.

FOUCAULT, M. As palavras e as coisas: uma arqueologia das ciências humanas. São Paulo: Martins Fontes, 1999. 
FREIRE, P. Pedagogia do oprimido. 17. ed. Rio de Janeiro: Paz e Terra, 1987.

GAMBOA, S. S. A dialética na pesquisa em educação: elementos de contexto. In: FAZENDA, I. (Org.). Metodologia da pesquisa educacional. 2. ed. São Paulo: Cortez, 1991, p. 91-115.

MORAES, MCM. Recuo da teoria: dilemas das pesquisas em educação. Revista Portuguesa de Educação. n.14, p. 7-25, 2001.

MORAES, MCM. A teoria tem consequências: indagações sobre o conhecimento no campo da educação. Educação e Sociedade. Campinas-SP: v.30, n.107, p.585-607, maio/ago, 2009.

ORLANDI, EP. Leitura e Discurso. Campinas-SP: Ed. Unicamp, 1998.

Artigo recebido em 10/06/2015

Aprovado em 02/09/2015 